\title{
Lusioersily
}

\section{Machine learning techniques for detecting electrode misplacement and interchanges when recording ECGs: A systematic review and meta-analysis}

Rjoob, K., Bond, RR., Finlay, D., McGilligan, V. E., Leslie, S. J., Rababah, A., Guldenring, D., Iftikhar, A., Knoery, C., McShane, A., \& Peace, A. (2020). Machine learning techniques for detecting electrode misplacement and interchanges when recording ECGs: A systematic review and meta-analysis . Journal of Electrocardiology, 62, 116-123. https://doi.org/10.1016/j.jelectrocard.2020.08.013

Link to publication record in Ulster University Research Portal

Published in:

Journal of Electrocardiology

Publication Status:

Published (in print/issue): 01/09/2020

DOI:

https://doi.org/10.1016/j.jelectrocard.2020.08.013

\section{Document Version}

Author Accepted version

\section{General rights}

Copyright for the publications made accessible via Ulster University's Research Portal is retained by the author(s) and / or other copyright owners and it is a condition of accessing these publications that users recognise and abide by the legal requirements associated with these rights.

\section{Take down policy}

The Research Portal is Ulster University's institutional repository that provides access to Ulster's research outputs. Every effort has been made to ensure that content in the Research Portal does not infringe any person's rights, or applicable UK laws. If you discover content in the Research Portal that you believe breaches copyright or violates any law, please contact pure-support@ulster.ac.uk. 


\section{Ulster}

\section{University}

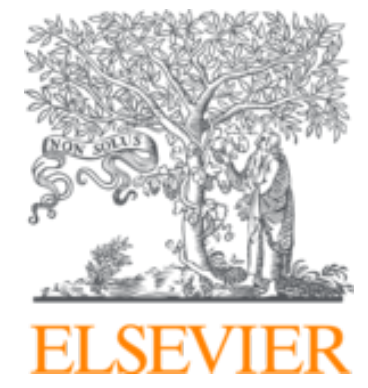

(C) <year>. This manuscript version is made available under the CCBY-NC-ND 4.0 license http://creativecommons.org/licenses/by-nc$\mathrm{nd} / 4.0 /$ 


\title{
Machine learning techniques for detecting electrode misplacement and interchanges when recording ECGs: A systematic review and meta-analysis
}

\author{
Khaled Rjoob, $\mathrm{MSc}^{\mathrm{a},{ }^{*}}$, Raymond Bond, $\mathrm{PhD}^{\mathrm{a}}$, Dewar Finlay, $\mathrm{PhD}^{\mathrm{a}}$, Victoria McGilligan, $\mathrm{PhD}{ }^{\mathrm{b}}$, Stephen J \\ Leslie, FRCP, PhD' ${ }^{c}$, Ali Rababah, MSc ${ }^{a}$, Daniel Guldenring, $\mathrm{PhD}^{\mathrm{d}}$, Aleeha Iftikhar, MSc ${ }^{a}$, Charles Knoery, \\ $\mathrm{MBChB}^{\mathrm{c}}$, Anne McShane, $\mathrm{MSc}^{\mathrm{e}}$, Aaron Peace, MB BCh BAO, PhD . \\ ${ }^{a}$ Faculty of Computing, Engineering \& Built Environment, Ulster University, Northern Ireland, UK. \\ ${ }^{\mathrm{b}}$ Faculty of Life \& Health Sciences, Centre for Personalised Medicine, Ulster University, Northern \\ Ireland, UK. \\ 'Department of Diabetes \& Cardiovascular Science, University of the Highlands and Islands, Centre \\ for Health Science, Inverness, UK. \\ ${ }^{\mathrm{d}}$ HTW Berlin, Wilhelminenhofstr. 75A, 12459 Berlin, Germany. \\ eEmergency Department, Letterkenny University Hospital, Donegal, Ireland. \\ ${ }^{f}$ Western Health and Social Care Trust, C-TRIC, Ulster University, Northern Ireland, UK.
}

Corresponding Author: Khaled Rjoob, MSc, Ulster University, School of Computing, Shore Road, Newtownabbey BT37 0QB, Northern Ireland, UK (rjoob-k@ulster.ac.uk)

\begin{abstract}
Introduction: Electrode misplacement and interchange errors are known problems when recording the 12-lead electrocardiogram (ECG). Automatic detection of these errors could play an important role for improving clinical decision making and outcomes in cardiac care. The objectives of this systematic review and meta-analysis is to 1) study the impact of electrode misplacement on ECG signals and ECG interpretation, 2) to determine the most challenging electrode misplacements to detect using machine learning $(\mathrm{ML}), 3$ ) to analyse the $\mathrm{ML}$ performance of algorithms that detect electrode misplacement or interchange according to sensitivity and specificity and 4) to identify the most commonly used $\mathrm{ML}$ technique for detecting electrode misplacement/interchange. This review analysed the current literature regarding electrode misplacement/interchange recognition accuracy using machine learning techniques. Method: A search of three online databases including IEEE, PubMed and ScienceDirect identified 228 articles, while 3 articles were included from additional sources from co-authors. According to the eligibility criteria, 14 articles were selected. The selected articles were considered for qualitative analysis and meta-analysis. Results: The articles showed the effect of lead interchange on ECG morphology and as a consequence on patient diagnoses. Statistical analysis of the included articles found that machine learning performance is high in detecting electrode misplacement/interchange except left arm/left leg interchange. Conclusion: This review emphasises the importance of detecting electrode misplacement detection in ECG diagnosis and the effects on decision making. Machine learning shows promise in detecting lead misplacement/interchange and highlights an opportunity for developing and operationalising deep learning algorithms such as convolutional neural network (CNN) to detect electrode misplacement/interchange.
\end{abstract}

Keywords: Machine learning; Lead misplacement; Electrode misplacement; Chest leads; Limb leads.

1. Introduction

The Electrocardiogram (ECG) represents the electrical activity of the heart as it is sensed by electrodes that are placed on the surface of the torso and limbs. The standard 12-lead ECG is the most commonly used method for heart rhythm analysis and it remains a cost-effective and efficient diagnostic tool [1]. Precise electrode placement when recording an ECG is very important as it is directly linked to the 
reliability and integrity of the signals that are interpreted to inform patients diagnostics and treatment [2-4]. There are two types of electrode placement errors, namely 1) electrode misplacement (e.g. precordial electrodes are misplaced in the wrong intercostal space) and 2) electrode interchange (e.g. the left arm electrode is placed on the right arm and vice versa).

ECG signals that are recorded using misplaced electrodes can lead to significant diagnostic errors made by physicians or computer-based algorithms that can exhibit false positive diagnoses of anterior infarction, ventricular hypertrophy, ischemia, or Brugada syndrome [5]. One study suggests that's electrode misplacement can lead to false diagnoses in $17-24 \%$ of patients [6]. Tomasic et al. [7] reported that 12-lead ECGs are less reliable if electrodes were misplaced, but also suggest that misplacement of up to $1 \mathrm{~cm}$ does not have a significant effect on the ECG. However, further work is needed to assess the impact of misplaced electrodes on the diagnostic sensitivity and specificity. The 12-lead ECG has a limited sensitivity (30-70\%) and specificity (70-95 \%) to detect acute coronary syndromes (ACS), which can look normal in most ACS for many reasons, one of which is electrode misplacement which can arises from mistakes made by clinicians [2][4]. Misplacement effects on synthesized 12-lead ECGs have been shown to cause differences in ECG interpretation. Body surface potential maps (BSPM) were used for the purpose of mimicking electrode misplacement in the 12lead ECG, for example Kania et al. [2] focused on studying the influence of precordial electrodes misplacement on P-wave morphology. ECG electrode interchange has been extensively studied for limb leads, such as the recognition of left leg (LL) and left arm (LA) reversal which is the most challenging limb lead interchange to detect. This lead interchange can conceal ECG abnormalities and might influence wrong therapy decisions [8]. The right arm (RA)/LL reversal in normal patients can create an ECG pattern suggestive of inferior wall $\mathrm{MI}$ and a non-sinus atrial rhythm. The RA/right leg $(\mathrm{RL})$ reversal has been reported to create a unique pattern of low voltage in the limb leads [9]. Electrode misplacement can conceal myocardial infarction or simulate a lateral wall $\mathrm{MI}$ in a true case of inferior wall MI [10]. Some of the aforementioned scenarios can lead to inappropriate diagnoses of STEMI patients [11]. Electrode misplacement is common even among experienced ECG technicians [12]. Finlay et al. [13] studied the effect of electrode misplacement on the EASI-derived 12-lead ECG system. They considered healthy, MI, and LVH subjects. They found that the EASI leads are less sensitive to electrode misplacement than the standard precordial leads.

Several methods have been suggested to improve electrode placement such as the electrode misplacement simulator (EMS), which is a web-based simulation that was developed to help train healthcare professionals in placing electrodes and to assist researchers to find new criteria or features that helps in the detection of electrode misplacement [14]. Beyond better training, researchers have also suggested the use of electrode belts, for example Bond et al. [15] evaluated the Cardio Quick Patch or CQP to help clinicians to accurately positioning chest electrodes during ECG acquisition recording. CQP significantly improved the accuracy of placing precordial electrodes V1, V3-V6 with little additional effort. Van Dam et al. [16] developed camera-based system using a KINECT depth camera to record the electrode positions. However, a large database is needed to calculate the sensitivity and specificity to determine accurately misplaced leads. Ultimately, to place the ECG electrodes correctly, a computed tomography (CT) can be used while recording and ECG but this requires a costly CT scan and an increase in radiation dose [2][3].In this paper, we conduct the first systematic review and meta-analysis on the topic of electrode misplacement/interchange detection using machine learning to show the importance of electrode misplacement/interchange detection and the performance of machine learning $(\mathrm{ML})$ to detect misplacement. This paper addresses the following research questions: 
1. Why detecting electrodes misplacement is important? and how interpretation could be affected by electrode misplacement/interchange?

2. What are the most sensitive electrodes regarding misplacement and what are the most frequently misplaced electrodes?

3. How ML has performed to detect misplacement? And what are the most frequently used ML techniques used to detect electrode misplacement?

4. What is the best ML algorithm to detect misplacement? And what are the most challenging electrode misplacements to detect using ML?

2. Methods

2.1 Literature search strategy

This systematic review paper was carried out according to the preferred reporting items for systematic reviews and meta-analyses (PRISMA) guidelines to identify all relevant studies. The literature search strategy was designed to investigate ECG electrode misplacement or lead interchange recognition using machine learning techniques. Online searches were performed using PubMed, IEEE and ScienceDirect databases from their dates of inception to September 2019 by two independent reviewers (Rjoob, Iftikhar). Search terms "ECG", "lead", "electrode", "cable", "displacement", "misplacement", and "interchange" were combined as keywords in different sequence of combination in order to achieve maximal search sensitivity.

\subsection{Selection criteria}

To screen all downloaded articles, inclusion criteria were used with the following conditions: 1 ) original studies in ECG lead misplacement recognition that are written in English, 2) clearly defined ECG dataset, features, method for misplacement detection, 3) type of electrode misplacement (vertical chest electrode misplacement, chest electrode switching or limb leads reversal/interchange). Studies were excluded if they did not use machine learning to detect misplacement or if the study did not clarify the ECG dataset or patient diagnosis. Two reviewers applied screening to avoid bias in the inclusion or exclusion process.

\subsection{Data extraction}

Data were extracted from each article using texts, figures and tables with any assessment made based on the extracted data. Two reviewers (Rjoob, Iftikhar) reviewed each article; any inconsistency was resolved by discussion to reach unanimity. Primary outcomes consisted of ECG types, features, machine learning algorithm, and the database details. Secondary outcomes included performance outcomes as measured by sensitivity and specificity.

3. Results

\subsection{Literature search}

The database searches identified a total of 228 articles, while 3 articles were included from additional sources. A total of 98 duplicate articles were removed and the remaining studies were subject to primary screening based on title and abstract. After the first primary screening, 105 articles were removed, and 28 studies underwent full review. Fourteen articles were included in the final qualitative synthesis and quantitative synthesis. There are differences between studies based on the type of electrode placement error (chest or $\operatorname{limb}$ ) and the features and machine learning algorithms being used. Figure 1 shows literature search using PRISMA guidelines. The included 14 studies for review are divided between four regions: 1) The USA $(n=4), 2)$ Sweden $(n=3), 3)$ Switzerland and Bulgaria $(n=3), 4)$ UK $(n=2)$ and 5) Netherlands $(n=2)$. The individual characteristics of included studies are summarized in Table 1. 


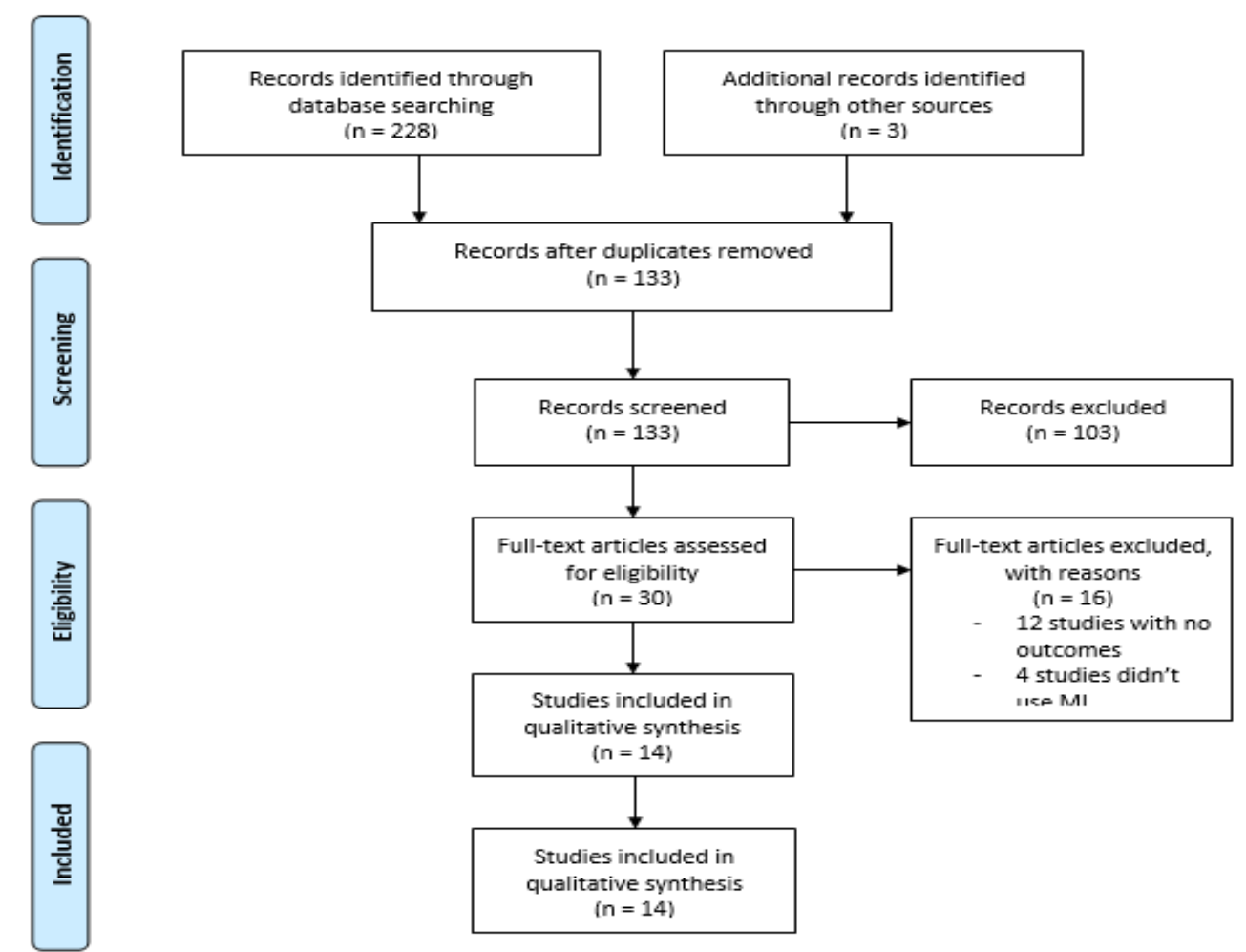

Fig. 1. PRISMA flow diagram of literature search strategy and selection.

\subsection{Study characteristics}

The fourteen studies used and evaluated $\mathrm{ML}$ based algorithms to detect electrode misplacement/interchange, and four ML models included artificial neural networks (ANNs) $(n=3)$ [17-19], decision trees (DT) $(n=5)$ [20-24], correlation $(n=3)$ [25-27], amplitude threshold $(n=1)$ [28], haisty $(n=1)$ [29] and support vector machines (SVM) $(n=3)$ [23-24][30]. The plurality of the studies $(n=7)$ focused on both limb and chest lead interchanges while other studies $(n=4)$ focused on limb lead interchanges only, two studies considered vertical misplacement of chest electrodes and one study considered chest lead interchange only. The majority of the studies $(n=12)$ used time domain (morphological) features as inputs to the machine learning, while other studies $(n=2)$ used time domain features, statistical features and time-frequency features. Ten studies used data that were extracted from 12 lead ECGs, while four studies considered body surface potential maps (BSPMs) and 12 leads ECGs. All articles could be divided into three domains: 1) chest electrode interchanges, 2) chest electrode misplacement and 3) limb electrode interchange. Results on the performance, methodological details and statistical measures used for the evaluation of performance of ML were provided for each study.

\subsection{Quality assessment}

The quality of an article was evaluated based on scoring system: 1) paper structure, 2) identify research objective clearly, 3) provide sufficient background information, 4) include suitable and acceptable practical experiment, 5) identify dataset clearly, 6) identify and report the results of the experiments clearly, 7) use appropriate methods to analyse the results. Cohen's kappa (at K=0.85) was computed to evaluate the agreement between the two reviewers, and there was an almost perfect agreement for eligibility of studies to be included in the review. Differences between the two reviewers were resolved with discussion between reviewers. Risk of bias in the included 14 studies was evaluated using quadas2 [31]. 
Table 1: Comparison between studies.

\begin{tabular}{|c|c|c|c|c|c|c|}
\hline REF & Dataset & Leads & Feature & Method & Sensitivity & Specificity \\
\hline $\begin{array}{l}\text { HAN C. ET AL., } \\
\text { [22] }\end{array}$ & $\begin{array}{l}\text { Body surface potential maps } \\
\text { and Physionet PTB diagnostic } \\
\text { ECG database }\end{array}$ & $\begin{array}{l}\text { LA-RA and RA-LL using } \\
\text { conventional and Mason } \\
\text { Likar } \quad \text { electrode } \\
\text { placements }\end{array}$ & $\begin{array}{l}\text { P-wave frontal axis, P-wave } \\
\text { clockwise vector loop rotation } \\
\text { direction, QRS frontal axis, QRS } \\
\text { clockwise vector loop rotation } \\
\text { direction, R-wave amplitude } \\
\text { and T-wave amplitude from } \\
\text { lead I and lead II. }\end{array}$ & DT & $\begin{array}{l}\text { Conventional ECGs (LA- } \\
\text { RA=91.3\%, RA-LL=72.8\%) and } \\
M L \text { ECGs (LA-RA=88.9\%, RA- } \\
L L=75.9 \%)\end{array}$ & 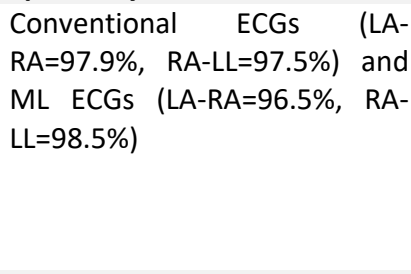 \\
\hline $\begin{array}{l}\text { GREGG R. ET AL., } \\
\text { [29] }\end{array}$ & $\begin{array}{l}\text { Adult 12-lead ECGs from a } \\
\text { single teaching hospital }\end{array}$ & RA-RL and LA-RL & $\begin{array}{l}\text { Maximum and minimum QRS } \\
\text { and T-wave voltages for ECG } \\
\text { leads I, II and III. }\end{array}$ & $\begin{array}{l}\text { DT } \\
\text { Haisty }\end{array}$ & $\begin{array}{l}\text { RA-RL } 84.2 \% \\
\text { LA-RL } 86.6 \% \\
\text { RA-RL=93.5\% } \\
\text { LA-RL=N/A }\end{array}$ & $\begin{array}{l}\text { RA-RL } 99.9 \% \\
\text { LA-RL } 99.9 \% \\
\text { RA-RL=99.4\% } \\
\text { LA-RL=N/A }\end{array}$ \\
\hline $\begin{array}{l}\text { JEKOVA I. ET AL., } \\
\text { [26] }\end{array}$ & $\begin{array}{l}\text { PTB diagnostic ECG database } \\
\text { and the Common Standards for } \\
\text { Electrocardiography (CSE) } \\
\text { database }\end{array}$ & $\begin{array}{l}\text { Precordial lead swaps } \\
\text { over V1-V6 }\end{array}$ & $\begin{array}{l}\text { QRS boundaries and QRS-T } \\
\text { pattern (QRS onset to QRS } \\
\text { offset }+350 \mathrm{~ms} \text { ) }\end{array}$ & Correlation & $\begin{array}{l}95.7 \% \text { (training) and 95\% } \\
\text { (testing) }\end{array}$ & $\begin{array}{l}93.5 \% \text { (training) and 91\% } \\
\text { (testing) }\end{array}$ \\
\hline $\begin{array}{l}\text { HEDEN B. ET AL., } \\
\text { [17] }\end{array}$ & $\begin{array}{l}\text { ECGs recorded at the } \\
\text { emergency department at the } \\
\text { University hospital in Lund }\end{array}$ & LA-LL and RA-LL & ECG signal & ANN & $\begin{array}{l}\text { LA-LL } 57.6 \% \\
\text { RA-LL } 80.5 \%\end{array}$ & $\begin{array}{l}\text { LA-LL 99.97\% } \\
\text { RA-LL 99.95\% }\end{array}$ \\
\hline $\begin{array}{l}\text { JEKOVA I. ET AL., } \\
\text { [25] }\end{array}$ & $\begin{array}{l}\text { CinC Challenge } 2011 \text { dataset } \\
\text { available from PhysioNet }\end{array}$ & $\begin{array}{l}\text { Chest leads and for } \\
\text { peripheral leads }\end{array}$ & $\begin{array}{l}\text { P-QRS-T amplitudes and } \\
\text { polarities in I, II, III }\end{array}$ & Correlation & $\begin{array}{l}96.8 \% \text { for peripheral leads and } \\
87 \% \text { for chest leads }\end{array}$ & $\begin{array}{l}97.8 \% \text { for peripheral and chest } \\
\text { leads }\end{array}$ \\
\hline JAN A. ET AL., [21] & The CSE database & $\begin{array}{l}\text { RA-LA V1-V2 } \\
\text { RA-LL V1-V6 } \\
\text { LA-LL V2-V3 V3-V4 } \\
\text { LL-RA-LA LA-LL-RA } \\
\text { V4-V5-V6-V1-V2-V3 } \\
\text { V6-V5-V4-V-3V2-V1 }\end{array}$ & Correlations between leads & DT & $\begin{array}{l}\text { Chest leads } 93.2 \% \text { and limb } \\
\text { leads } 81.5 \%\end{array}$ & $\begin{array}{l}\text { Chest leads } 99.8 \% \text { and limb } \\
\text { leads } 99.8 \%\end{array}$ \\
\hline $\begin{array}{l}\text { HAN C. ET AL., } \\
{[30]}\end{array}$ & $\begin{array}{l}\text { Body surface potential maps } \\
\text { and Physionet PTB diagnostic } \\
\text { ECG database }\end{array}$ & $\begin{array}{l}\text { LA-RA, RA-LL, V1-V2, } \\
\text { V1-V3, V2-V3, V3-V4, } \\
\text { V4-V5, V4-V6, V5-V6, } \\
\text { and no lead swap) }\end{array}$ & $\begin{array}{l}\text { Including both morphology } \\
\text { features and redundancy } \\
\text { features }\end{array}$ & SVM & $\begin{array}{l}\text { Precordial cables interchanges } \\
\text { were } 56.5 \% \text { and limb cable } \\
\text { interchange (excluding left } \\
\text { arm-left leg interchange) were } \\
93.8 \%\end{array}$ & $\begin{array}{l}\text { Precordial cable interchange } \\
\text { was } 99.9 \% \text {, and limb cable } \\
\text { interchange (excluding left } \\
\text { arm-left leg interchange) was } \\
99.9 \% \text {. }\end{array}$ \\
\hline $\begin{array}{l}\text { JEKOVA I. ET AL., } \\
\text { [27] }\end{array}$ & $\begin{array}{l}\text { Database from the Basel } \\
\text { University Hospital, Physionet } \\
\text { PTB diagnostic ECG database } \\
\text { and the CSE diagnostic } \\
\text { database }\end{array}$ & $\begin{array}{l}15 \text { possible pairwise } \\
\text { reversals in standard } \\
\text { precordial leads }\end{array}$ & Morphology features & Correlation & $\begin{array}{l}\text { Chest electrodes } 97.9 \% \text { and } \\
\text { limb electrodes } 97.4 \%\end{array}$ & $\begin{array}{l}\text { Chest electrodes } 97.4 \% \text { and } \\
\text { limb electrodes } 99.2 \%\end{array}$ \\
\hline
\end{tabular}




\begin{tabular}{|c|c|c|c|c|c|c|}
\hline & \multicolumn{6}{|c|}{ Table 1 continued } \\
\hline BIE J. ET AL., [28] & $\begin{array}{l}\text { Large }(\mathrm{N} 18,000) \text { hospital } \\
\text { database for which serial ECG's } \\
\text { were available and was based } \\
\text { on simulated juxtaposition }\end{array}$ & $\begin{array}{l}\text { RA-LA, V1-V2 } \\
\text { LA-LL, V2-V3 } \\
\text { RA-LL, V3-V4 } \\
\text { LA-RL, V4-V5 } \\
\text { RA-RL, V5-V6 }\end{array}$ & $\mathrm{P}, \mathrm{Q}, \mathrm{R}$, and $\mathrm{S}$ amplitudes & $\begin{array}{l}\text { Algorithm is based on QRS } \\
\text { axis and } P \text { amplitudes for } \\
\text { limb electrode reversals, and } \\
\text { PQ-RS amplitude distances }\end{array}$ & $\begin{array}{l}\text { Chest electrodes } 88.7 \% \text { and } \\
\text { limb electrodes } 54.6 \%\end{array}$ & $\begin{array}{l}\text { Chest electrodes } 99.8 \% \text { and } \\
\text { limb electrodes } 99.6 \%\end{array}$ \\
\hline $\begin{array}{l}\text { KORS J. ET AL., } \\
\text { [20] }\end{array}$ & $\begin{array}{l}\text { Database of } 1,220 \text { standard } 12- \\
\text { lead ECGs collected in the } \\
\text { Common Standards for } \\
\text { Quantitative ECG project }\end{array}$ & $\begin{array}{l}\text { RA-LA, V1-V2, V3-V4, V5- } \\
\text { V6 } \\
\text { RA-LL, V1-V3, V4-V5 } \\
\text { LA-LL, V2-V3, V4-V6 }\end{array}$ & Averaged representative beats & DT & $\begin{array}{l}\text { RA-LA 99.3\%, V3-V4 99.3\% } \\
\text { RA-LL 98,3\%, V4-V5 98.3\% } \\
\text { LA-LL 53.6\%, V4-V6 87.2\% } \\
\text { V } 1 \text {-V2 98.3\%, V5-V6 90.6\% } \\
\text { V1-V3 97.5\%, V2-V3 95.6\% }\end{array}$ & $\begin{array}{l}\text { RA-LA 100\%, V3-V4 100\% } \\
\text { RA-LL 100\%, V4-V5 100\% } \\
\text { LA-LL 95.6\%, V4-V6 } 99.5 \% \\
\text { V1-V2 100\%, V5-V6 } 99.8 \% \\
\text { V1-V3 100\%, V2-V3 } 99.5 \%\end{array}$ \\
\hline $\begin{array}{l}\text { HEDEN B. ET AL., } \\
\text { [18] }\end{array}$ & $\begin{array}{l}\text { The study was based on } 11,432 \\
\text { ECGs }\end{array}$ & RA-LA & $\mathrm{P}, \mathrm{QRS}$, and ST-T measurement & ANNs & $95 \%$ & $99.95 \%$ \\
\hline $\begin{array}{l}\text { HEDEN B. ET AL., } \\
\text { [19] }\end{array}$ & $\begin{array}{l}\text { 11,432 ECGs, The emergency } \\
\text { department at the University } \\
\text { Hospital in Lund }\end{array}$ & $\begin{array}{l}\text { LA-LL, V3-V4 } \\
\text { V } 1-V 2, \text { V4-V5 } \\
\text { V2-V3, V5-V6 }\end{array}$ & QRS amplitude and Area & ANNs & $\begin{array}{l}\text { LA-LL 57.6\%, V3-V4 } 77.5 \% \\
\text { V1-V2 80.6\%, V4-V5 83.0\% } \\
\text { V2-V3 44.5\%, V5-V6 73.2\% }\end{array}$ & $\begin{array}{l}\text { LA-LL 99.97\%, V3-V4 99.95\% } \\
\text { V1-V2 99.9\%, V4-V5 99.95\% } \\
\text { V2-V3 99.87\%, V5-V6 99.88\% }\end{array}$ \\
\hline $\begin{array}{l}\text { RJOOB K. ET AL., } \\
\text { [23] }\end{array}$ & $\begin{array}{l}\text { Body surface potential maps } \\
\text { and Physionet PTB diagnostic } \\
\text { ECG database }\end{array}$ & $\begin{array}{l}\text { V1 and V2 vertical } \\
\text { misplacement }\end{array}$ & $\begin{array}{l}\text { Morphological features }(P, Q, R \text {, } \\
S \text { and } T \text { amplitudes), statistical } \\
\text { features and WT }\end{array}$ & $\begin{array}{l}\text { SVM, DT and logistic } \\
\text { regression }\end{array}$ & $\begin{array}{l}\text { V1 } 89.8 \% \\
\text { V2 } 86.6 \%\end{array}$ & $\begin{array}{l}\text { V1 } 88.5 \% \\
\text { V2 } 86.6 \%\end{array}$ \\
\hline $\begin{array}{l}\text { RJOOB K. ET AL., } \\
\text { [24] }\end{array}$ & $\begin{array}{l}\text { Body surface potential maps } \\
\text { and Physionet PTB diagnostic } \\
\text { ECG database }\end{array}$ & $\begin{array}{l}\text { V1 and V2 vertical } \\
\text { misplacement }\end{array}$ & $\begin{array}{l}\text { Morphological features }(\mathrm{P}, \mathrm{Q}, \mathrm{R} \text {, } \\
\mathrm{S} \text { and } \mathrm{T} \text { amplitudes), statistical } \\
\text { features, correlation } \\
\text { coefficients and WT }\end{array}$ & $\begin{array}{l}\text { SVM, DT, logistic regression } \\
\text { and bagged decision tree }\end{array}$ & V1 and V2 93.3\% & V1 and V2 92.0\% \\
\hline
\end{tabular}

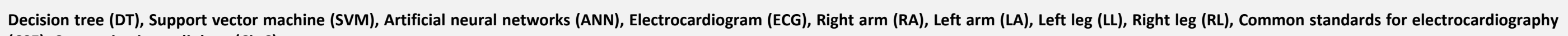
(CSE), Computing in cardiology (CinC) 


\subsection{Descriptive summary of results}

Sensitivity and specificity were the most frequently used measures to evaluate the performance of $\mathrm{ML}$ algorithms to detect misplaced electrodes (where the outcome is binary, i.e. correct electrode position or incorrect electrode position). Sensitivity was used in all studies while specificity was not available in two studies. In the five studies that used DT, the sensitivity ranged from $17.9 \%$ to $99.3 \%$ and specificity ranged from $86.6 \%$ to $100 \%$. When using ANNs, the sensitivity ranged from $44.5 \%$ to $99.9 \%$ ) and specificity ranged from $99.8 \%$ to $99.9 \%$. In the three other studies that used correlation; the sensitivity ranged from $87.0 \%$ to $97.8 \%$ while specificity was not provided in these two studies but was mentioned in one study as $91.0 \%$. SVM was used in three studies, and the sensitivity ranged from $56.5 \%$ to $93.8 \%$ and specificity ranged from $86.6 \%$ to $99.9 \%$. A new amplitude threshold algorithm was used in one study, the sensitivity was $20.0 \%-90.0 \%$ and specificity was $~ 99.8 \%$. Bagged tree was used in two studies, the sensitivity was $84.2 \%-93.3 \%$ and specificity was $92.0 \%-99.9 \%$ and Haisty was used in one study, and the sensitivity was $84.2 \%$ and specificity was $99.9 \%$. For chest electrode interchanges, the sensitivity between the studies varied from $44.5 \%$ to $99.95 \%$ and specificity varied from $91 \%$ to $100 \%$. While in limb electrode interchanges, the sensitivity between the studies varied from $20 \%$ to $99.3 \%$ and specificity varying from $95.6 \%$ to $100 \%$. All included studies were divided into three groups: 1) chest electrode interchanges, 2) chest electrode misplacement and 3) limb electrode interchanges (lead reversal). Table 2 below shows mean sensitivity and mean specificity of each group.

Table 2: Mean sensitivity and specificity of each group.

\begin{tabular}{|c|c|c|c|c|c|c|}
\hline & Ref & Mean Se & SD & Mean Sp & SD & F1 \\
\hline \multirow[t]{9}{*}{ A } & Jekova I. et al., [26] & $97.9 \%$ & \pm 0.31 & $99.1 \%$ & \pm 0.19 & $98.5 \%$ \\
\hline & Kors J. et al., [20] & $95.2 \%$ & \pm 4.25 & $99.8 \%$ & \pm 0.21 & $97.4 \%$ \\
\hline & Jan A. et al., [21] & $93.2 \%$ & \pm 6.4 & $99.8 \%$ & \pm 0.11 & $96.4 \%$ \\
\hline & Bie J. et al., [28] & $88.7 \%$ & \pm 8.80 & $99.8 \%$ & \pm 0.08 & $93.9 \%$ \\
\hline & Heden B. et al., [19] & $71.6 \%$ & \pm 14.01 & $99.91 \%$ & \pm 0.03 & $93.8 \%$ \\
\hline & Jekova I. et al., [27] & $95.3 \%$ & \pm 0.35 & $92.2 \%$ & \pm 1.25 & $93.8 \%$ \\
\hline & Jekova I. et al., [25] & $87.0 \%$ & \pm 0.00 & $97.8 \%$ & \pm 0.00 & $92.0 \%$ \\
\hline & Han C. et al., [30] & $56.1 \%$ & \pm 27.7 & $99.9 \%$ & \pm 0.04 & $71.8 \%$ \\
\hline & & Average $=85.6 \%$ & $S D= \pm 13.5$ & Average $=98.5 \%$ & $S D= \pm 2.5$ & \\
\hline \multirow[t]{3}{*}{ B } & Rjoob K. et al., [23] & $79.6 \%$ & \pm 8.6 & $84.6 \%$ & \pm 5.9 & $81.6 \%$ \\
\hline & Rjoob K. et al., [24] & $81.5 \%$ & \pm 11.5 & $81.0 \%$ & \pm 11.0 & $81.3 \%$ \\
\hline & & Average $=80.5 \%$ & $S D= \pm 0.95$ & Average $=82.8 \%$ & $S D= \pm 1.8$ & \\
\hline \multirow[t]{12}{*}{ C } & Jekova I. et al., [26] & $97.4 \%$ & \pm 1.88 & $99.2 \%$ & \pm 0.35 & $98.3 \%$ \\
\hline & Heden B. et al., [18] & $95.0 \%$ & \pm 0.00 & $99.95 \%$ & \pm 0.00 & $97.4 \%$ \\
\hline & Jekova I. et al., [25] & $96.8 \%$ & \pm 0.00 & $97.8 \%$ & \pm 0.00 & $97.3 \%$ \\
\hline & Han C. et al., [30] & $93.4 \%$ & \pm 1.05 & $99.9 \%$ & \pm 0.05 & $96.5 \%$ \\
\hline & Gregg R. et al., [29] & $88.1 \%$ & \pm 3.90 & $99.7 \%$ & \pm 0.20 & $93.5 \%$ \\
\hline & Kors J. et al., [20] & $83.7 \%$ & \pm 21.31 & $98.5 \%$ & \pm 2.07 & $90.4 \%$ \\
\hline & Jan A. et al., [21] & $81.5 \%$ & \pm 31.8 & $99.8 \%$ & \pm 0.18 & $89.7 \%$ \\
\hline & Han C. et al., [22] & $82.5 \%$ & \pm 9.25 & $97.7 \%$ & \pm 0.20 & $89.3 \%$ \\
\hline & Heden B. et al., [17] & $69.0 \%$ & \pm 11.45 & $99.9 \%$ & \pm 0.01 & $81.6 \%$ \\
\hline & Heden B. et al., [19] & $57.6 \%$ & \pm 0.00 & $99.97 \%$ & \pm 0.00 & $73.1 \%$ \\
\hline & Bie J. et al., [28] & $54.6 \%$ & \pm 28.09 & $99.6 \%$ & \pm 0.15 & $70.5 \%$ \\
\hline & & Average $=81.7 \%$ & $S D= \pm 14.5$ & Average $=99.2 \%$ & $S D= \pm 0.82$ & \\
\hline
\end{tabular}

A Represents chest electrode interchanges, B represents chest electrode vertical misplacement and C represents limb electrode interchanges. 
In each group, $\mathrm{ML}$ performance in electrode misplacement/interchanges was evaluated for each possible electrode misplacement/interchanges according to sensitivity and specificity as shown in figure 2 and F1 score as shown in figure 3. While figure 4 shows each ML algorithm performance particularly in each scenario.

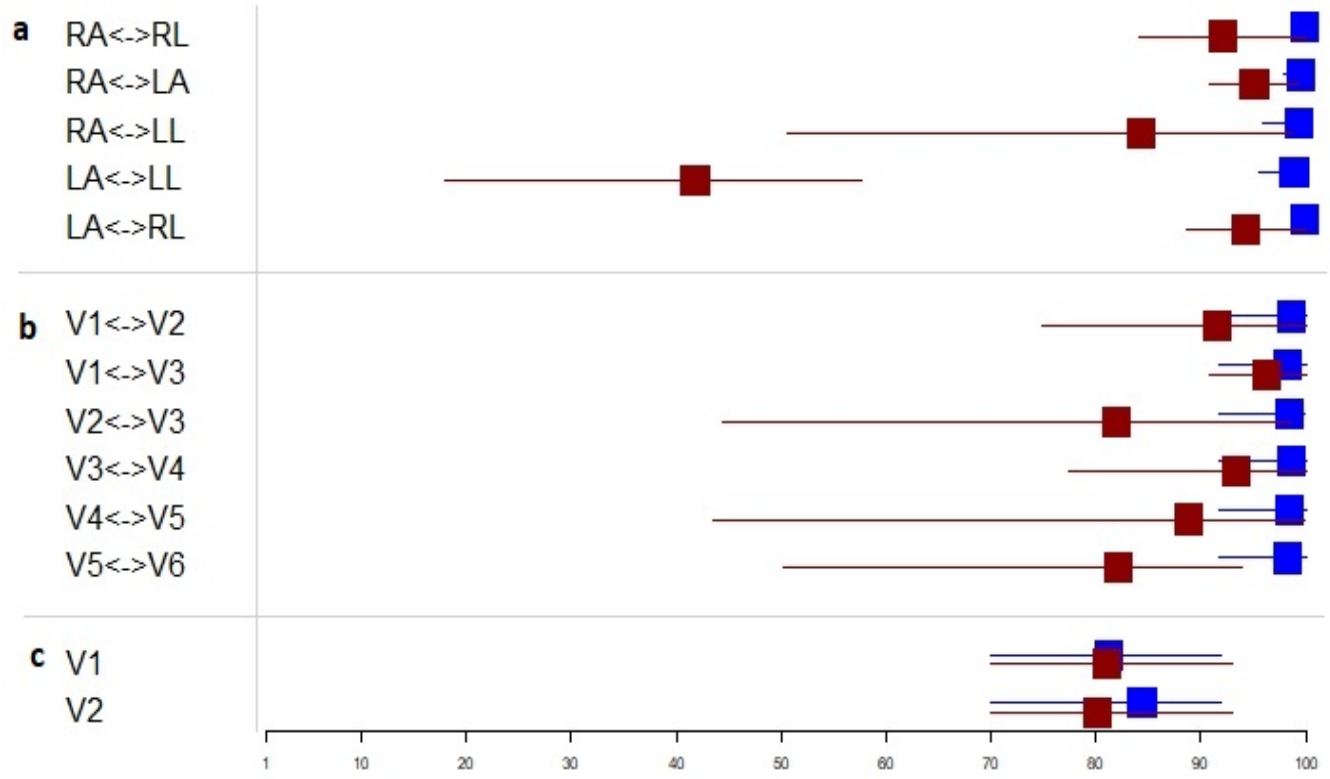

Figure 2: ML performance in each possible electrode misplacement/interchanges, a: represents limb electrode interchanges, b: represents chest electrodes interchanges and c: represents vertical misplacement of V1 and V2. Right arm (RA), left arm (LA), left leg (LL), right leg (RL).

$$
\begin{aligned}
& \mathrm{RA}<>\mathrm{RL} \\
& \mathrm{RA}<->\mathrm{LA} \\
& \mathrm{RA}<->\mathrm{LL} \\
& \mathrm{LA}<->\mathrm{LL} \\
& \mathrm{LA}<->\mathrm{RL} \\
& \mathrm{V} 1<->\mathrm{V} 2 \\
& \mathrm{~V} 1<->\mathrm{V} 3 \\
& \mathrm{~V} 2<->\mathrm{V} 3 \\
& \mathrm{~V} 3<->\mathrm{V} 4 \\
& \mathrm{~V} 4<->\mathrm{V} 5 \\
& \mathrm{~V} 5<->\mathrm{V} 6 \\
& \mathrm{~V} 1 \\
& \mathrm{~V} 2
\end{aligned}
$$

\section{Summary}

Figure 3: F1 score of ML for each possible electrode misplacement/interchanges. Right arm (RA), left arm (LA), left leg (LL), right leg (RL). 

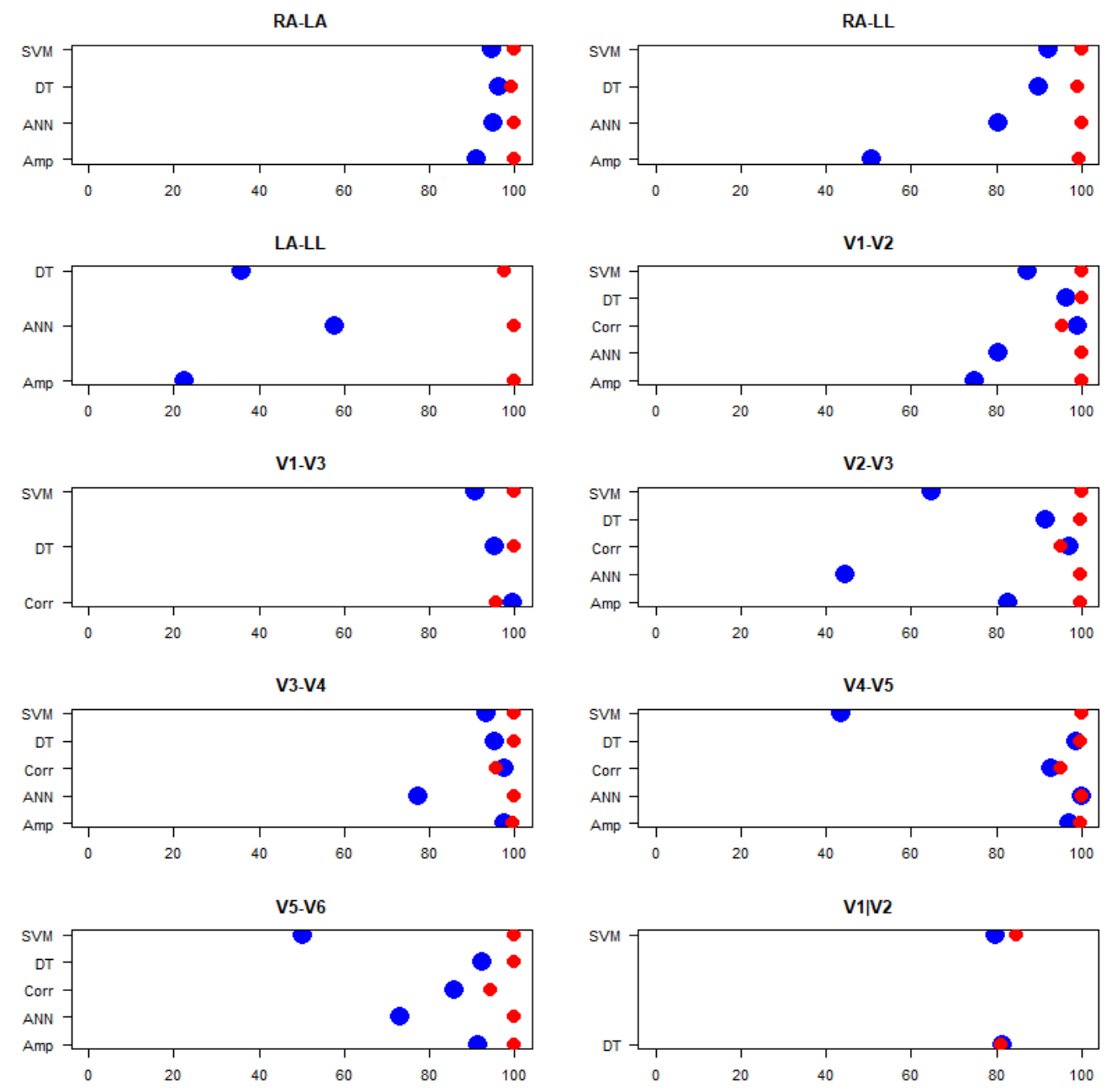

Figure 4: ML algorithms performance in each scenario of common electrode interchange/misplacement, blue circles represent sensitivity and red circles represent specificity. Decision Tree (DT), correlation (Corr), support vector machine (SVM), artificial neural networks (ANNs), amplitude (Amp), right arm (RA), left arm (LA), left leg (LL), right leg (RL).

\section{Discussion}

The aim of this systematic review and meta-analysis paper is to identify and analyse articles that implement machine learning in the area of automated lead misplacement or interchange recognition. Different articles show the implications of electrode interchanges on decision making in cardiac care and intensive care units which have the highest figures reported for electrode misplacement and how this error can mimic different types of cardiac diseases which could result in a false diagnosis [5][12][32]. Bupp et al. [33], found that electrode misplacement can occur between $40 \%$ to $60 \%$ of the time. And according to Wegner et al. [34], 36\% of chest electrodes are placed outside a radius of 1.25 in. Various methods were developed to prevent lead misplacement, but only 14 articles used ML to detect electrode interchange/misplacement. None of 14 articles considered deep learning (DL) to detect lead interchange/misplacement, while they used traditional ML. The 14 articles were divided into various groups for each analysis to provide accurate results. According to meta-analysis, ML obtained the highest sensitivity and specificity when detecting chest electrode interchanges (switching) compared to limb electrode interchanges and chest electrode misplacement (vertically). Classical ML can detect limb lead interchange with a high degree of performance based on sensitivity and specificity except LA/LL interchange, which is still unresolved with currently low performance 
(sensitivity<57\%) [17][19][20][26]. At the time of writing, there has been no research using deep learning to detect lead misplacement or to improve the performance of LA/LL detection. Changes in P-wave morphology were found to be statistically significant if precordial leads V1 and V2 were misplaced by $2 \mathrm{~cm}$, while morphology changes were not prominent when precordial leads $\mathrm{V} 3, \mathrm{~V} 4$ and V5 were misplaced by up to $5 \mathrm{~cm}$ from their gold standard location. In addition, the precordial lead V1 was found to be more sensitive to vertical than to horizontal misplacements which is in contrary to other leads which can result in false diagnoses or false negatives [2][5]. Furthermore, Misplacement of $\mathrm{V} 1$ and $\mathrm{V} 2$ can change the amplitude of R-waves in these leads as per intercostal space away from the correct position, which can result in an interpretation of old anterior myocardial infarction [5] [12]. Hence, healthcare providers should take this into account when recording ECGs [4][6]. Table 3 below shows answers of all key research questions that have been investigated in this study.

Table 3: Key research questions that have been answered by this systematic review.

\section{Question}

1. Why detecting electrodes misplacement is important? and how interpretation could be affected by electrode misplacement/interchange?

2. What are the most sensitive electrodes regarding misplacement and what are the most frequently misplaced electrodes?

3. How ML has performed to detect misplacement? And what are the most frequently used $\mathrm{ML}$ techniques used to detect electrode misplacement?

4. What is the best ML algorithm to detect misplacement? And what are the most challenging electrode misplacements to detect using ML?

\section{Answer}

ECGs with electrode misplacement can simulate abnormalities such as ectopic rhythm, chamber enlargement or myocardial infarction, which can lead to significant diagnostic errors such as false positive diagnoses of anterior infarction, ventricular hypertrophy, ischemia, or Brugada syndrome [5][32]. Also, vertical misplacement of V1 and V2 can show a spurious $\mathrm{rSr}^{\prime}$ pattern [35].

$\mathrm{V} 2$ is the most sensitive misplaced electrode with regards to the change in the signal followed by V3, V4 and V1 [4]. While V1 and V2 are the most frequent misplaced electrode (>50\%) [34].

According to meta-analysis, ML showed a high sensitivity and specificity to detect electrode misplacement/interchanges, except LA-LL interchange. DT was the most commonly used ML algorithm to detect lead misplacement/interchange ( 5 out of $14,35.7 \%$ ). While the other ML algorithms were used less than four times in the 14 articles (21.4\%). According to the ten most common lead misplacement/interchange scenarios as shown in figure 4, DT obtained the best performance five times out of the ten scenarios. While other ML algorithms obtained the best performance less than 4 times. However, as shown in the metaanalysis, LA-LL is the most challenging electrode misplacement/interchange scenario for $M L$ to solve, it's challenging in intensive care units, especially in the absence of a comparative ECG [36].

\section{Conclusion}

This systematic review was conducted to evaluate the performance of published lead interchange detection algorithms. Our findings highlight opportunities for enhancing ECG data quality and clinical decision making through the accurate detection of lead misplacement. Precordial lead waveform changes with the vertical misplacement of the precordial electrodes can cause implications on ECG interpretation. Incorrect electrode placement could change the diagnostic interpretation of the 12lead ECG and consequently patient treatment. These findings highlight the importance of developing new algorithms such as deep learning to detect electrode misplacement and interchange errors with a high sensitivity and specificity, especially to detect LA-LL interchange. 
Author contributors: All authors were responsible for study conception. All were responsible for design, analysis and interpretation of results. All were responsible for revising the manuscript.

Declarations of interest: none.

Funding: This work is supported by the European Union's INTERREG VA programme, managed by the Special EU Programmes Body (SEUPB). The work is associated with the project - 'Centre for Personalised Medicine - Clinical Decision Making and Patient Safety'. The views and opinions expressed in this study do not necessarily reflect those of the European Commission or the Special EU Programmes Body (SEUPB). Grant number is IVA5036.
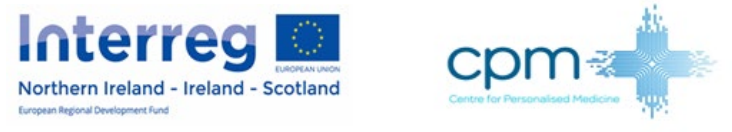

References:

[1] Suh W. et al. Importance of electrocardiography in the assessment and management of heart failure: a case report. Journal of Electrocardiology. Vol.41, pp.44-48, 2008.

[2] Kania M. et al. The Effect of Precordial Lead Displacement on P-wave Morphology in Body Surface Potential Mapping. Computing in Cardiology 2013. Vol.40, pp.531-534, 2013.

[3] Alioui S. et al. Automatic Registration of 3D Camera Recording to Model for Leads Localization. Computing in Cardiology 2017. VOL 44, 2017.

[4] Kania M. et al. The effect of precordial lead displacement on ECG morphology. Med Biol Eng Comput. Vol.52, pp.109-119, 2014.

[5] Walsh B. et al. Misplacing V1 and V2 can have clinical consequences. American Journal of Emergency Medicine. Vol.36, pp.865-870, 2018.

[6] Bond R. et al. The effects of electrode misplacement on clinicians' interpretation of the standard 12-lead electrocardiogram. European Journal of Internal Medicine. Vol. 23, pp.610615, 2012.

[7] Tomasic I. et al. Impact of electrode misplacement on the accuracy of 12-lead ECG synthesized from differential leads. MIPRO 2015. 25-29 May 2015, pp.365-369, Opatija, Croatia.

[8] jekova I. et al. Detection of Electrode Interchange in Right Precordial and Posterior ECG Leads. Computing in Cardiology 2015. Vol.42, pp.1149-1152, 2015.

[9] Pérez-Riera A. et al. Main artifacts in electrocardiography. Ann Noninvasive Electrocardiol. Vol.23, pp.1-8, 2018.

[10]Rudiger A. et al. Influence of Electrode Misplacement on the Electrocardiographic Signs of Inferior Myocardial Ischemia. AMERICAN JOURNAL OF EMERGENCY MEDICINE. Vol.21, pp.574-577, 2003.

[11]Cairns A. et al. A computer-human interaction model to improve the diagnostic accuracy and clinical decision-making during 12-lead electrocardiogram interpretation. Journal of Biomedical Informatics Vol.64, pp.93-107,2016.

[12]Soliman E.. A simple measure to control for variations in chest electrodes placement in serial electrocardiogram recordings. Journal of Electrocardiology. Vol.41, pp.378-379, 2008.

[13]Finlay D. et al. Effects of electrode placement errors in the EASI-derived 12-lead electrocardiogram. Journal of Electrocardiology. Vol.43, pp.606-611, 2010.

[14]Bond R. et al. A simulation tool for visualizing and studying the effects of electrode misplacement on the 12-lead electrocardiogram. Journal of Electrocardiology. Vol.44, pp.439444, 2011. 
[15]Bond R. et al. Human factors analysis of the CardioQuick Patch ${ }^{\circledR}$ : A novel engineering solution to the problem of electrode misplacement during 12-lead electrocardiogram acquisition. Journal of Electrocardiology. Vol.49, pp.911-918, 2016.

[16]Van Dam B. et al. New Computer Program for detecting 12 Lead ECG Misplacement using a 3D Kinect Camera. Computing in Cardiology 2013. Vol.40, pp.1175-1178, 2013.

[17]Heden B. et al. Misplacement of the Left Foot ECG Electrode Detected by Artificial Neural Networks. Computers in Cardiology 1995, pp.225-228, 1995.

[18]Heden B. et al. Artificial Neural Networks for Recognition of Electrocardiographic Lead Reversal. Am J Cardiol. Vol.75, pp.929-933, 1995.

[19]Heden B. et al. Detection of Frequently Overlooked Electrocardiographic Lead Reversals Using Artificial Neural Networks. Am J Cardiol. Vol.78, pp.600-604, 1996.

[20]Kors J. and Herpen j. A Novel Method to Detect Electrocardiographic Electrode Interchanges. Journal of Electrocardiology. Vol.33, pp.209-210, 2000.

[21]Jan A. et al. Accurate Automatic Detection of Electrode Interchange in the Electrocardiogram. The American Journal of Cardiology. Vol. 88, pp.396-399, 2001.

[22] Han C. et al. Automatic Detection of ECG Lead-wire Interchange for Conventional and MasonLikar Lead Systems. Computing in Cardiology 2014, Vol.41, pp.145-148, 2014.

[23]Rjoob K., Bond R. et al. Data driven feature selection and machine learning to detect misplaced V1 and V2 chest electrodes when recording the 12-lead electrocardiogram. Journal of $\begin{array}{llll}\text { Electrocardiology, } \quad \text { Vol.57, } & \text { Pages }\end{array}$ https://doi.org/10.1016/j.jelectrocard.2019.08.017

[24]Rjoob K., Bond R. Machine Learning Improves the Detection of Misplaced v1 and v2 Electrodes During 12-Lead Electrocardiogram Acquisition. CinC 2019. https://doi.org/10.22489/CinC.2019.035

[25]jekova I. et al. Recognition of Diagnostically Useful ECG Recordings: Alert for Corrupted or Interchanged Leads. Computing in Cardiology 2011, Vol.38, pp.429-432, 2011.

[26] jekova I. et al. Detection of Electrode Interchange in Precordial and Orthogonal ECG Leads. Computing in Cardiology 2013, Vol.40, pp.519-522.

[27]jekova I. et al. Inter-lead correlation analysis for automated detection of cable reversals in 12/16-lead ECG. computer methods and programs in biomedicine. Vol.134, pp.31-41, 2016.

[28]Bie J. et al. The development and validation of an early warning system to prevent the acquisition of 12-lead resting ECGs with interchanged electrode positions. Journal of Electrocardiology. Vol.47, pp.794-797, 2014.

[29]Gregg R. et al. Detecting ECG Limb Lead-wire Interchanges Involving the Right Leg Lead-wire. Computing in Cardiology 2017, Vol.44, pp.1-4, 2017.

[30] Han C. et al. Automatic detection of ECG cable interchange by analyzing both morphology and interlead relations. Journal of Electrocardiology. Vol.47, pp.781-787, 2014.

[31]Whiting PF, Rutjes AWS, Westwood ME, et al. QUADAS-2: a revised tool for the quality assessment of diagnostic accuracy studies. Ann Intern Med 2011; 155:529-36. doi:10.7326/0003-4819-155-8-201110180-00009.

[32]Batchvarov V. et al. Incorrect electrode cable connection during electrocardiographic recording. Europace. Vol.9, pp.1081-1090, 2007.

[33]Bupp J. et al. Placement of cardiac electrodes: written, simulated, and actual accuracy. Crit Care. Vol.6, pp.457-62,1997.

[34]Wenger W. and Kligfield P. Variability of precordial electrode placement during routine electrocardiography. J Electrocardiol, Vol.29, vpp.179-84, 1996.

[35] Baranchuk A. et al. Differential diagnosis of $\mathrm{rSr}^{\prime}$ pattern in leads V1-V2. Comprehensive review and proposed algorithm. Ann Noninvasive Electrocardiol 2015;20:7-17.

[36]Velagapudi P. et al. Left arm/left leg lead reversals at the cable junction box: A cause for an epidemic of errors. Journal of Electrocardiology, Vol.50, pp.111-114, 2017 https://doi.org/10.1016/j.jelectrocard.2016.06.011. 